\title{
Reform designing of the civil engineering graduate design program
}

\author{
Yingli Liu,Bingxuan Du,Junhong Huan \\ College of Civil Engineering and Architecture, \\ Hebei United University, \\ Tangshan.China \\ e-mail: lylseff@126.com ,dbx19881230@163.com , junhong_love@126.com
}

\begin{abstract}
Graduation design is one of the most important parts of the teaching plan in universities, it's also extremely important in practical education; Graduation design plays an important role in higher education, for it is a large-scale training that the student can make comprehensive use of what they have learned before they get to their working posts. In this paper, take civil engineering as an example, analysising and discussing the graduation design scheme.
\end{abstract}

Keywords- civil engineering; graduation design; reform designing; practicality; construction design

Nowadays our state council tries their best to vigorously promote the reform of training talent mode reform and, which is an important measure to intensify the educational reform and promote the quality-oriented education in an all-round way. Therefore, the undergraduates we cultivate are application-oriented talents and who are adept with technology. In order to adapt to needs of the community, to adapt to the characteristics of field working and to highlight our practical and targeted, to strengthen the cultivation of practice ability, to improve the students' comprehensive quality become the highlight of the reform of higher education. In the teaching content, we should design the training program and knowledge, ability, quality structure, which are based on developing the application ability of the student. Only in this way can the undergraduate not only possess moderate basic theoretical knowledge, but also have strong ability of technology application. Moreover the construction of the new curriculum and teaching content system must put "practical" at the first place, which can highlight its characteristics of pointedly and practicality.

Graduation design is one of the most important parts of the teaching plan in universities, it's also extremely important in practical education; Graduation design plays an important role in higher education, for it is a large-scale training that the student can make comprehensive use of what they have learned before they get to their working posts. In addition, whether the direction of the design is appropriate, whether the contents of the design are reasonable and the amounts of the work have great influence on the students' ability that adapt quickly to the field work. And now, take civil engineering as an example; meanwhile I will talk something about the graduation project plan in teaching.

\section{THE DEFICIENCY OF THE TRADITIONAL GRADUATION DESIGN}

The traditional graduation design of civil engineering is based on the structure design, with a small amount of supplemented construction organization design and budget preparation. However, from the actual situation, it is usually has nothing to do with the work they do after graduation. For example, some students' graduation designs are frame structure design, nevertheless, what they do after graduation are construction. This is the so called disconnection. This disconnect phenomenon mainly caused by the traditional teaching method. And it's inevitable to some extent. As a result it became one of the most urgent problems to solve right now.

So far, areas that are ripe for the development of the design of building structures, moreover computers have been widely applied in this field, and it already formed a complete, stereotyped design process and diffusely used standard excogitations. From design objectives and the development trends of structure, we can draw a conclusion that the style of the buildings, which we designed, should be towards more artistic, graceful, new and modern; the cost of construction should be lower. And the new theories, new materials, new equipments and new technology should be widely applied to the construction. As an undergraduate, who is limited by the extent of knowledge they have learned, can hardly meet these requirements, let alone make innovations. So, they have to indiscriminately borrow the experience of predecessors. What's worse, the training cannot achieve the expected goal, for the students always try to imitate (some even copy) the previous ones without understanding the substance.

\section{REQUIREMENT OF EMPLOYERS FOR GRADUATES}

First, look at the nature of the work undertaken by the higher vocational graduates who are major in civil engineering, structural design is also incompatible with the work that most civil engineering graduates engaged in currently. When being assigned to the construction sites, their primary works are engineering construction, which requires the ability of reading blueprints accurately and knowing well about construction technology, while the knowledge of structural design is rarely needed. And from the perspective of practical, it is meaningless that a student who will be engaged in the job of construction, while 
his or her graduation project is architectural structure design, and vice versa.

Secondly, no matter what job they do structural design or construction after graduate from school, unfamiliar with soft wares which are used in structural design or construction organization design will directly affect employers' trust and student's signing rate. In addition, implementing item management of laboratory facilities in construction is extremely common at construction sites, and it demands a capable and vigorous construction team. Besides, the seasoned managers must possess high quality of management. That means employees must master the knowledge of design of construction organization, design and construction of temporary structure, reasonable use and assign of labor, material and mechanics, construction measurement and test, financial management and so forth. Basically the person who is capable with above abilities equivalent to a project manager, and it requires a relative high comprehensive quality. If graduates only have the knowledge on structural design, they will not competent in the job.

Therefore, in order to meet the requirements of market, the university should work on cultivating person with certain application ability. Education and teaching methods of graduate design must center on practical and training project. Only transform the original structure design into construction design, can it palatable to the requirement.

\section{REQUIREMENTS OF CONSTRUCTION SITE FOR GRADUATION DESIGN}

1 Features of construction site and construction design

The diversity of conditions in construction site determine the complexity and variability in construction design; construction design has the characteristic of multiple quantity, various forms and high randomness, so its importance is self-evident. Multiple quantities in construction design refer to so many unpredictable temporary projects in the constructions. The scene of the topography is varied. With limited resources, in order to ensure the lowest cost, fastest and safest construction progress, the construction program and progress must be selected reasonably and suitably. The construction design has high randomness, it is important to adjust the program at any time based on the actual situation, so that determine the construction progress reasonably.

It is hard to consider very considerately, such as whether a temporary structure can eventually be used for construction, the installing and dismantling in the use of process is convenient or not, is it can be used repeatedly. Only through practical application, can the problems be found, and then the better program would be explored. Sometimes, it is possible to change the design, the finally goal can be achieved after constantly repeating. Needless to say the importance of temporary structure, in order to ensure the construction process getting smoothly, each structure must be safe and reliable; otherwise it will lead to a major accident.

2 Requirements in field work for graduation design

Based on these features, it is hard for the graduates who never worked in the field to design the temporary structure. If the design principles, methods, inspecting calculation of temporary structure can be added to the graduation design and excised, focusing on be familiar with the application of various norms and parameter values, then some problems can be solved. If the graduation design content and graduation practice can be combined, then the better effect will be achieved. For example, the student may find the construction company uses A program in the field, then he can use B program in his graduation design. Through comparing the two different programs, on one hand, the students' thinking modes can be developed, on the other hand, they can master the methods and steps in structure design. Of course, if the scope of design could be expanded, students can draw inferences from one case to another case, then the situation of graduates working in the field at a loss can be changed, and they can adapt to the field work quickly.

\section{SUGGESTIONS TO GRADUATION DESIGN REFORM}

1. Do serious research on employment-trends before graduation, by which assign design assignment.

2. Contact with the enterprise that should be responsible for the graduation designs of students under different employment circumstances to inform the change that the graduation designs be carried through under the help of both tutors from the enterprise and his college. Since the graduation design are normally finished under the help of only his college tutor.

3. Strengthen the cultivation of structural design software, construction software, budget software understanding and application capabilities of students.

4. For civil engineering, each student should be equipped with the necessary software, which needs to be equipped with a set of 30 people the network version PKPM design software (including structural design, construction, budget module).

5 Decompose the relevant content with graduation design into each relevant course consciously, digest and solve part of the graduation project, and this is a kind of method to extend the graduation design. At the same time, the students could be encouraged to learn each course purposely, so that the teaching process of each course can develop in a continuous and systematic way. The graduation design content act as a clue which runs through the whole school system and major course learning, and it urges the students to build and develop the concept of overall situation in local learning gradually.

6 After all the courses finished, about 8 to 10 weeks could be taken out to evaluate the students' programs and integrate them according to building and structure design, at the same time to improve their programs from the perspective of construction drawing design.

7. Have these basis, 3 to 4 weeks can be used to collect the building, structure design results, then the construction drawings of building, structure can be made. This process could allow students to re-read the actual construction plans of similar projects, draw construction plans on target. In this way, the results of graduation design can be further improved. 
In summary, the teaching progress of graduation design in civil engineering can use targeted project management method. As long as the arrangement is reasonable, the measures are in place, and then the graduation design could be made more perfect, the quality be improved. In this situation, the students could have a relatively complete concept about building structure, strong ability to identify and interpret the figures, they could adapt to the needs of different work facing with building projects. At last, the "zero distance" docking between education and jobs can be achieved, so that the characteristic of civil engineering undergraduate education can be showed.

[1] Department of Higher Education. Both teaching and learning (basic knowledge of higher vocational education teachers) [M]. Beijing: Higher Education Press, 2004.

[2] Guan. G, and Hao. T, Civil engineering professional courses and graduate design training reform [J]. Higher Education, vol.4. 2004, pp. 117-119.

[3] Ni. M. J, Creating the future [M]. Zhejiang University Press.1999, pp.307.

[4] Pan. M. J, Education quality of mass higher education [J]. Jiangsu Higher Education Press, vol.1. 2000, pp. 6-10.

[5] Zhu. Q. P, Liu. J. Z, and Hao. C. S, The actual state and reform on college(engineering) graduation design. Study of Contemporary Education (Scientific Research and Teaching). vol.15. Dec. 2007,pp.53-55. 